\title{
Lötschberg basistunnel - en tunnel til tiden
}

\section{Af geolog Erik Karlsen}

Schweizernes nyeste jernbanetunnel, den næsten $35 \mathrm{~km}$ lange Lötschberg Basistunnel, har givet nye oplysninger til beskrivelsen af Alpernes geologi. Samtidig har den været et eksempel til efterfølgelse på, hvorledes et projekt kan blive færdigt til den planlagte tid, når blot man tager de rigtige forholdsregler.

Onde tunger påstår, at den egentlige årsag til at bore den netop færdiggjorte 34,6 km lange togtunnel under Alperne mellem de schweiziske kantoner Bern og Wallis, var at forsyne skiområderne i Wallis med dagtursturister fra de større byer i det nordlige Schweiz.

Hvad årsagen end har været, så er den her nu, og de første skiturister fra nord har allerede kunnet bruge en togforbindelse, der er langt hurtigere end tidligere. Andre - med helt andre interesser som fx Alpernes geologi - kan også bruge den nye forbindelse. De mange års sonderinger og prøveboringer både i forbindelse med forundersøgelser, og også mens selve bore- og sprængningsarbejdet stod på, har givet en lang række nye og

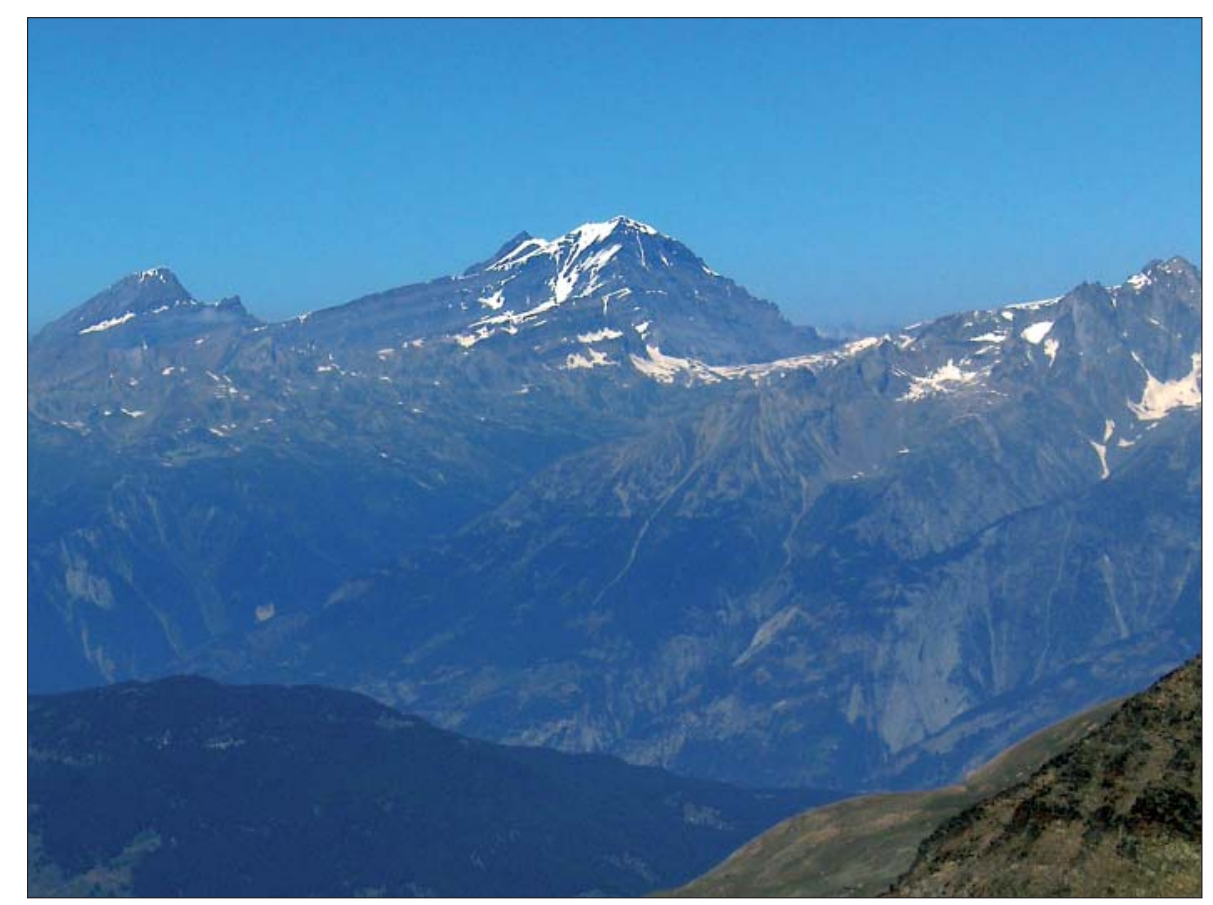

$3 \mathrm{~km}$ under toppen af Balmhorn, det markante bjerg i midten af billedet, der her ses fra sydøst, skcerer den nye jernbanetunnel gennem en af Alpernes hovedkceder. (Foto: Erik Karlsen)

til dels overraskende oplysninger om, hvad der gemmer sig i undergrunden.

\section{Omfattende forundersøgelser}

Mellem 1991 og 1999 blev der gennemført 27 boringer i op til 1,4 km's dybde. Derudover blev der boret en 9,4 km lang sonderingstunnel, og i tillæg hertil har især tunneler i forbindelse med vandkraftværker og selvfølgelig også den eksisterende 14,6 km lange togtunnel en halv km højere givet oplysninger om den geologiske beskaffenhed. Endelig er der inde fra tunnelen, hvor den har været færdigboret, været lavet talrige sonderingsboringer op til en halv $\mathrm{km}$ frem for at undgå slemme overraskelser under arbejdet.

På baggrund af forundersøgelserne regnede geologerne med en række zoner, der hver især kunne give deres problemer at slås med. Set fra nord ville der efter ca. $13 \mathrm{~km}$ først være kalkbjergarterne i DoldenhornDecke og den hosliggende såkaldte Autochthon Nord med meget varierende bjergarter. Den næste problemzone ville være den vandførende Jungfraukeil efter ca. 23 km, og endelig skulle der være en problematisk zone lige ved den sydlige tunnelindgang.
En anden undersøgelse bestod i fra den sydlige indgangs to parallelle rør at teste to forskellige metoders effektivitet, nemlig boring med en tunnelboremaskine eller sprængning. På en strækning over 3,4 km, hvor geologien i de to rør var fuldstændigt ens, skulle man først igennem 500 meter gnejs, herefter 150 meter med bl.a. lerskifer og dolomit, hvorefter man skulle kæmpe sig igennem sedimenterne i Gampel-Baltschieder Autochthon (se profilet øverst på næste side). Endelig sluttede forsøgsstrækningen af med granodiorit.

En af konklusionerne var, at tunnelboremaskinen reagerede mere følsomt på lokale ustabiliteter som fx knæk i kalkbænke. Også hårde bjergarter gjorde borearbejdet betydeligt langsommere. Samlet set var det dog på forsøgsstrækningen mellem $1 \frac{1}{2}$ og 21/2 gange så hurtigt at bore som at sprænge. Alligevel er ca. $80 \%$ af hele tunnelen sprængt og kun ca. $20 \%$ boret.

\section{Vandførende huler}

Set fra nord var den første prognosticerede problemzone kalken i Doldenhorn-decke, som man vidste kunne indeholde vandførende karststrukturer med vandtryk op til 


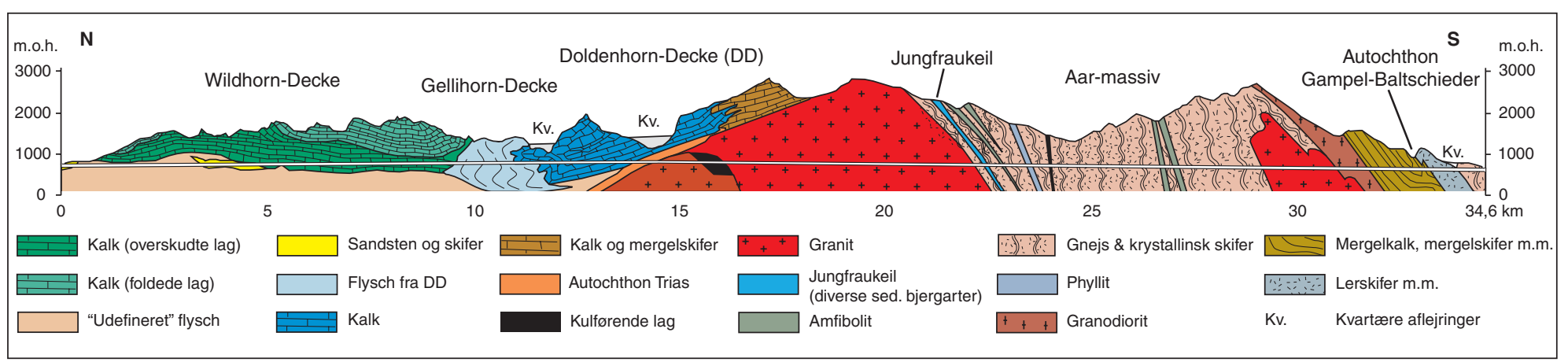

Geologisk profil over tunnelstrckningen i forenklet udgave. Mere detaljerede udgaver kan findes gennem bl.a. BLS's hjemmeside og det geologiske institut for Berns universitet. Navnene er navngivne formationer i området. (Grafik: Erik Karlsen, modificeret efter flere schweiziske kilder, herunder iscr BLS AG)

75 bar, samt det efterfølgende autochthone område, der regnedes for at være meget ustabilt. For ikke at blive ubehageligt overrasket af indstrømmende vand, der kunne komme med flere tusind liter i sekundet, og som man før har set det andre steder i verden, blev der inde fra tunnelen lavet op til en halv km lange horisontale sonderingsboringer. Herefter blev geologien undersøgt ved hjælp af borehulslogning og enkelte kerneprøver.

Derudover målte man det hydrauliske tryk i borhullerne ved en kontrolleret udstrømning af vand. På den måde var det muligt at forudsige, om man skulle regne med vandførende strukturer de næste få hundrede meter.

Alt i alt viste de faktiske forhold sig at være mere gunstige, end prognoserne havde forudset.

\section{Granit og kul}

Herefter var man nået til Aar-massivet, og man regnede med ikke at løbe ind i overraskelser de næste $7 \mathrm{~km}$. Men allerede efter få hundrede meter granit dukkede der pludselig sedimentlag op bestående af bl.a. sandsten og mergelskifer, og senere stødte
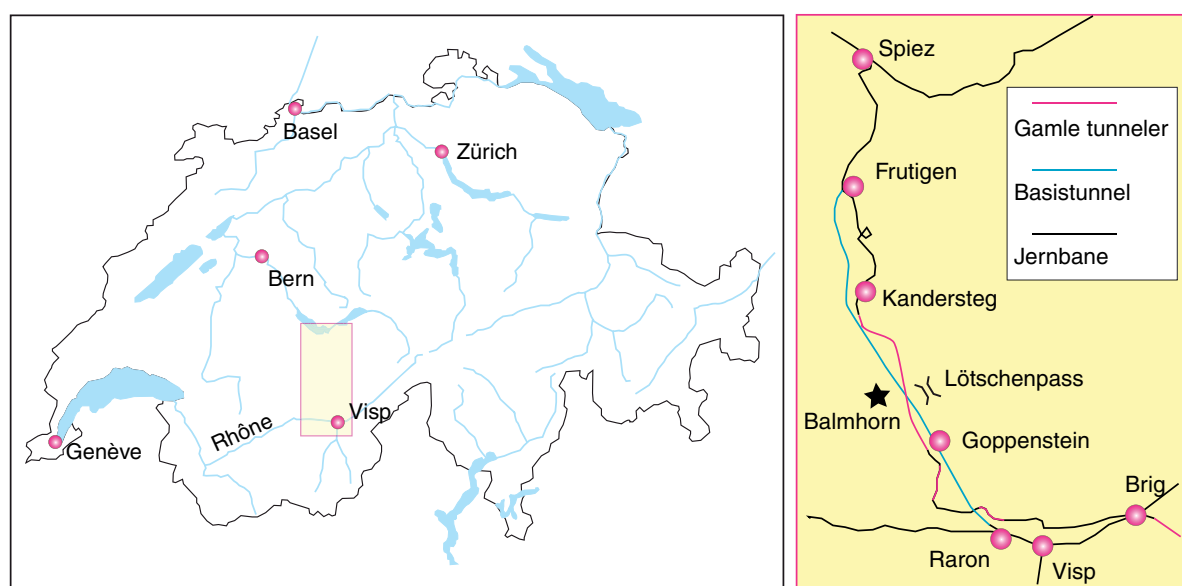

Oversigtskort over Schweiz med det indtegnede område forstørret op. Bemcerk, at den gamle banelinie krydser sig selv. Det sker ved en sløjfe gennem en tunnel i bjerget. På den måde overvinder den gamle bane større højdeforskelle. Den nye tunnel indeholder mere, end der er vist på tegningen. Således er der ekstra til-og afkørsler samt tvcertunneler. Alt i alt blev der boret og sprcengt $88 \mathrm{~km}$ tunnel. Stjernen illustrerer en bjergtop. (Grafik: Erik Karlsen) man endda på antracit! Også i nærheden af sedimenterne i Jungfraukeil kom man flere gange gennem mindre lag af antracit.

Fundet af lagene fra Karbon midt i granitten skabte stor opmærksomhed og foranledigede en journalist ved en schweizisk avis til at hævde, at man nu skulle til at skrive lærebøgerne om Alpernes geologi om. Imidlertid er kullag ikke en sjældenhed i Alperne og kan findes flere steder Schweiz. Blot havde man ikke regnet med at finde det netop her, for der var intet på overfladen, der tydede på sådanne lag, og man havde anset området for at være meget homogent.

Analyserne af fossiler, der blev fundet i lagene, gav en alder på 300 millioner år.

\section{Geologisk status}

Ud over de beskrevne problemzoner var der en række mindre af slagsen, der dog også gav tunnelarbejderne noget at slås med. Eksempelvis var man nødt til at tætne de vandførende sedimentlag i Jungfraukeil, sydlige del skete der skader, da uforudsete tørveområder satte sig som følge af dræning af området. og i landsbyen St. German over tunnelens
Alt i alt viste de geologiske forudsigelser sig dog at stemme godt overens med de faktiske forhold, både på de bjergartsmæssige, hydrologiske og tektoniske områder.

Næsten 17 millioner tons bjergarter blev fjernet ved tunnelarbejdet, og heraf blev ca. $40 \%$ genanvendt til sikringer, tunnelvægge m.m.

Banen er dimensioneret til hastigheder op til ca. $250 \mathrm{~km} / \mathrm{t}$, men ved en testkørsel i december 2006 nåede et tysk ICE-tog op på 288 km/t. Selv godstoge skal køre med hastigheder på op til 160 km/t.

\section{En tunnel til tiden}

Da man efter de indledende undersøgelser indledte det egentlige tunnelarbejde i år 2000, aftalte man med den schweiziske forbundsstat, at tunnelen med spor og tekniske installationer skulle stå klar den 1 . juni 2007, og at den egentlige køreplansmæssige drift skulle kunne starte den 9. december 2007.

Fra større projekter ved enhver, at det er vanskeligt at overholde datoer så langt frem i tiden. Men som følge af de omfattende geologiske forundersøgelser og den intelligente planlægning med hensyn til yderligere undersøgelser, mens arbejdet stod på, lykkedes det at indvie tunnelen kun 2 uger efter den planlagte frist. Og tunnelen indgik i den normale togdrift præcist til den dato, der var blevet fastsat 7 år tidligere.

Ligeledes har de økonomiske forudsigelser vist sig at være meget præcise. Hvor prognosen sagde, at tunnelen vil koste omkring 4.365 millioner SFr., viste en opgørelse fra 30. juni 2007, at prisen endte på 4.301 millioner Sfr.

\section{Schweizisk tunnel-infrastruktur}

Af og til har spørgsmålet lydt, hvorfor man borer tunneler til toge og ikke til biler. Som det er de fleste bekendt, udgør Schweiz en barriere for trafikken mellem Nordeuropa og Italien. Før tunnelernes tid blev denne barriere overvundet over bjergpassene, som dog normalt var ufremkommelige mindst halvdelen af året. Med jernbanernes indtog fra midten af det nittende århundrede begyndte man også at bore og sprænge tunne- 


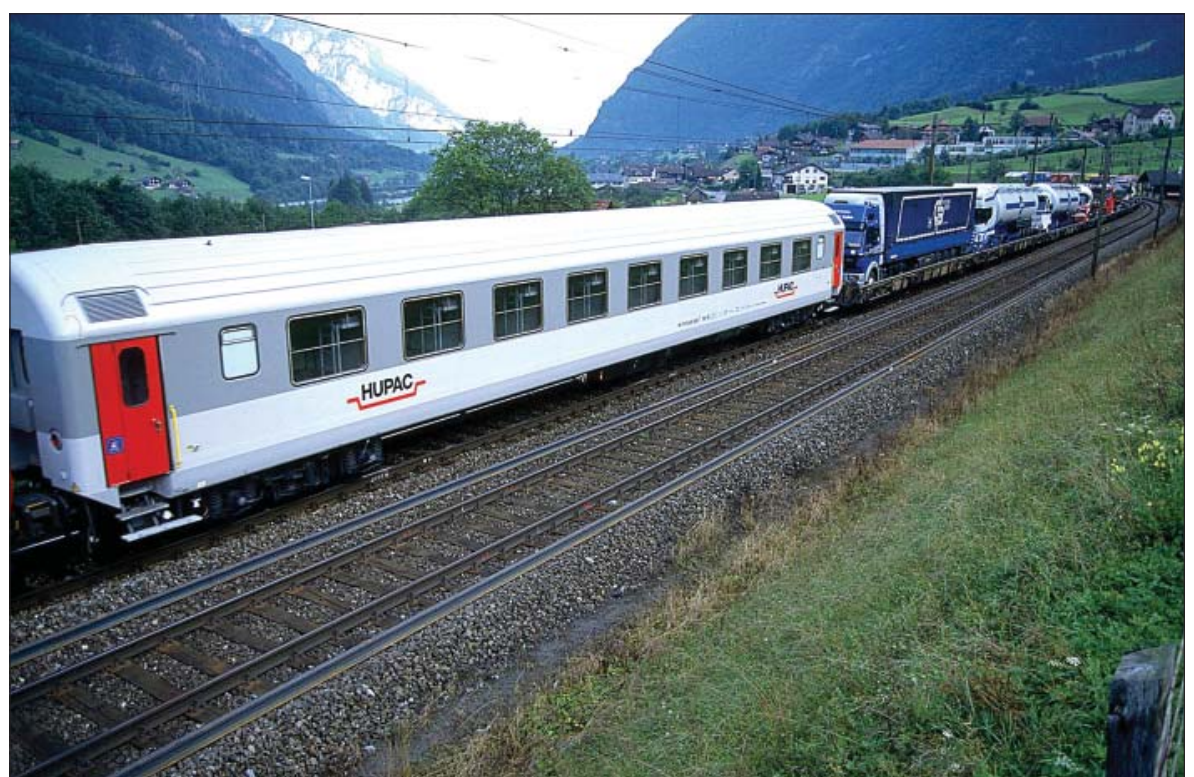

Lastbiler kører op på togvogne og transporteres således gennem Alperne, mens chaufføren hviler ud i en separat togvogn, der følger med scttet. Dette er fremtidens fleksible transportform. (Foto og copyright: Hupac SA, Schweiz)

\section{Den første Lötschberg-tunnel}

Ca. en halv km højere end den nye basistunnel løber en anden jernbanetunnel gennem bjerget mellem Kandersteg og Goppenstein (se kortet). Den 14,6 km lange tunnel blev taget i brug i 1913 , og strækningen var fra første dag elektrificeret!

Oprindeligt var tunnelen planlagt til en længde på 13,7 km, men ved sprængningen af et område med et uventet sedimentlag trængte sand og slam ind tunnelen og dræbte 26 tunnelarbejdere. Kun en af dem lykkedes det at grave fri igen. Først ville man fortsætte af den planlagte linie, men til sidst valgte man at mure den gamle tunnelgang til, hvor- ved de 25 resterende tunnelarbejdere fandt sig en grav i det indre af bjerget. Herefter fortsatte man i en ny linie, som var 900 meter længere end den gamle, men som ikke længere gav problemer.

Da de to tunnelrør fra nord og syd mødtes, var det med en horisontal fejl på under $26 \mathrm{~cm}$ og en vertikal på godt og vel $10 \mathrm{~cm}$.

Efter at basistunnelen er taget i brug, har den gamle Lötschberg-tunnel selvfølgelig mistet en del af sin betydning, men den bruges dog stadig til regional trafik og al transport af personbiler. Ifølge planen skal den klare 66 tog om dagen. ler. Lange tunneler til biler er af nyere dato, men man ser igen en tendens til at gå bort fra dem igen. Således er der ingen planer om at bore et ekstra rør til biltunnelen under Gotthard-passet. Et ekstra tunnelrør ville ellers give en kraftig forøgelse af kapaciteten og forkorte transporttiden for især lastbiler.

I stedet har man i Schweiz en tradition for at transportere biler gennem tunnelerne med tog, et foretagende der er stærkt effektiviseret. Bl.a. er der i den gamle 14,6 km lange Lötschberg-tunnel, der ligger en halv km højere end den nye basistunnel (se boks), kun højst 10 minutters ventetid for biler, der skal transporteres mellem kantonerne Bern og Wallis.

Også på lastbilsiden er dette sat i system. Således tilbyder et schweizisk jernbaneselskab at samle lastbiler op i Sydtyskland og fragte dem igennem Alperne til Norditalien. Chaufføren kører med i en separat togvogn og kan køre lastbilen fra borde, når toget ankommer til sit bestemmelsessted. Derved bevares fleksibiliteten ved at bruge lastbiler i stedet for containere. Når man tæller ophold ved grænseovergange med, er denne transportform langt hurtigere, end hvis lastbilen skulle krydse Alperne ved egen hjælp.

\section{Mere om tunneler og geologi}

Er man interesseret i flere informationer, end denne lille artikel har kunnet give, er der udkommet en bog med bidrag til et symposium. Bogen indeholder artikler på både tysk og engelsk: Simon Löw (Red.): Geologie und Geotechnik der Basistunnels am Gotthard und am Lötschberg. 1. oplag, 2006. ISBN 3728130826.

Desuden har jernbaneselskabet BLS (Bern-Lötschberg-Simplon), der står for driften af tunnelen, udgivet en række skrifter om projektet.

\section{Geologisk tidsskala}

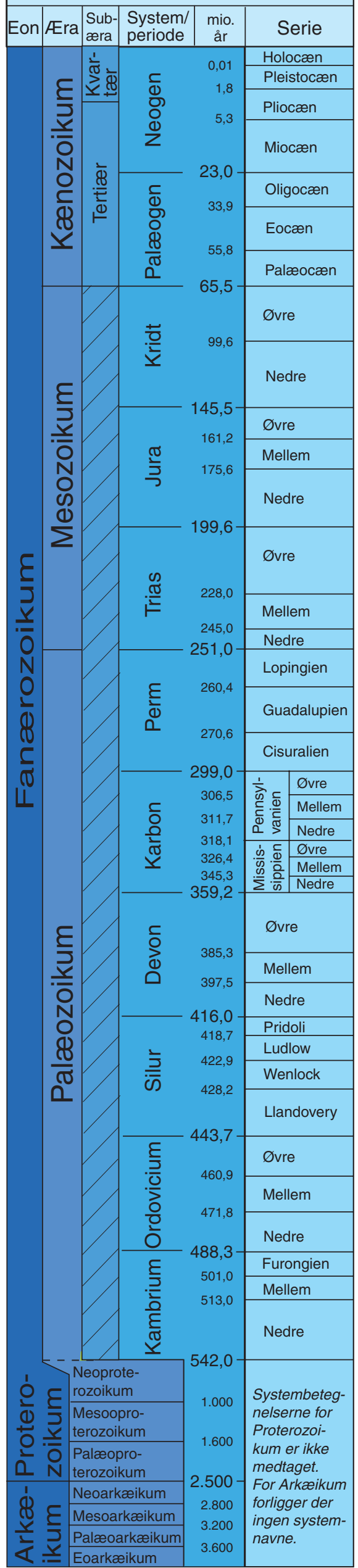

